\title{
Comparison of modified Friedewald's formula with direct measurement of low-density lipoprotein cholesterol in Bangladeshi population
}

\author{
Chowdhury $\mathrm{N}^{1}$, Saiedullah $\mathrm{M}^{2}$, Khan $\mathrm{MAH}^{3}$, Rahman $\mathrm{MR}^{4}$ \\ ${ }^{1}$ Department of Biochemistry, Chattagram Maa-O-Shishu Hospital Medical College, Chittagong, ${ }^{2}$ Department \\ of Applied Laboratory Sciences, Bangladesh University of Health Sciences (BUHS), Dhaka, ${ }^{3}$ Department of \\ Biochemistry, Enam Medical College, Savar, Dhaka, ${ }^{4}$ Department of Biochemistry, Delta Medical College, \\ Dhaka. Email: drnasreenchy@yahoo.com
}

\begin{abstract}
A modification of Friedewald's formula to estimate serum low-density lipoprotein cholesterol (LDLC) up to serum triglyceride (TG) level of $11.3 \mathrm{mmol} / \mathrm{L}$ in Bangladeshi population has recently been published. The aim of this study was to compare the modified formula with direct measurement of LDLC in Bangladeshi population in a different setting. One thousand and fifty two specimens from adult subjects were analyzed. Serum total cholesterol (TC), high-density lipoprotein cholesterol (HDLC), LDLC and TG were measured by standard methods. The modified Friedewald's formula was applied to estimate LDL cholesterol concentration. Results were expressed as mean \pm SD and calculated LDLC was compared with measured LDLC by two-tailed paired t test, Bland-Altman plot for absolute bias, Pearson's correlation coefficients of calculated LDLC with measured LDLC and Passing \& Bablok regression equation of calculated LDLC against measured LDLC. The mean \pm SD of measured LDLC was $2.98 \pm 0.82 \mathrm{mmol} / \mathrm{L}$. LDLC calculated by modified Friedewald's formula was $2.77 \pm 0.86 \mathrm{mmol} / \mathrm{L}$. The mean absolute bias was $-0.20 \pm 0.32 \mathrm{mmol} / \mathrm{L}$, Pearson's correlation coefficient (r) was $0.9293(P<0.0001)$ and Passing \& Bablok regression equation was $y=-0.3856+1.0597 x$ for modified formula up to serum $\mathrm{TG} \leq 11.3 \mathrm{mmol} / \mathrm{L}$. Compared to original Friedewald's formula, performance of the modified Friedewald's formula was better up to serum $\mathrm{TG} \leq 4.52 \mathrm{mmol} / \mathrm{L}$. The study reveals that the modified Friedewald's formula may be used to calculate LDLC approximately in Bangladeshi population.
\end{abstract}

\section{Introduction}

Serum low-density lipoprotein cholesterol (LDLC) is an independent risk factor for the development of coronary heart disease $\mathbf{~}^{\mathbf{1}}$. It is the recommended primary basis for treatment and correct classification in risk categories ${ }^{2}$. The reference method for the measurement of serum LDLC is the $\beta$-quantification ${ }^{3}$. Due to the technical difficulties associated with the reference method, new generation direct homogeneous methods have been developed and recommended for the measurement of LDLC as an alternative $\mathbf{4 , 5}$. The direct methods are costly and require expensive automation and are not affordable by most of the laboratories in the developing countries like ours. As a result Friedewald's formula ${ }^{6}$, the most widely used formula, is generally used for the estimation of LDLC by most of the laboratories in Bangladesh. According to Friedewald's formula, LDLC can be calculated from three other lipid parameters, ie, serum total cholesterol (TC), serum triglycerides (TG) and serum high-density lipoprotein cholesterol (HDLC) by the formula LDLC $=\mathrm{TC}-$
TG/2.2 - HDLC (in SI units) ${ }^{6}$. One of the most important limitations of the Friedewald's formula is that it cannot be used when fasting serum TG concentration is above $4.52 \mathrm{mmol} / \mathrm{L}(400 \mathrm{mg} / \mathrm{dL})$. But a large population study showed that Friedewald's formula can be used up to serum TG concentration of $9.0 \mathrm{mmol} / \mathrm{L}(796.5 \mathrm{mg} / \mathrm{dL})$ with caution $^{7}$. Another recent study in Chinese population showed that modification of Friedewald's formula [LDLC $=0.9$ TC -0.1 TG -0.9 HDLC in conventional units] improved the accuracy up to serum TG concentration of 11.3 $\mathrm{mmol} / \mathrm{L}$ (1000 mg/dL) compared to Friedewald's formula ${ }^{\mathbf{8}}$. Modification of the Friedewald's formula for the estimation of LDLC up to serum TG concentration of $11.3 \mathrm{mmol} / \mathrm{L}(1000 \mathrm{mg} / \mathrm{dL})$ by adjusting the bias using serum TG to TC ratio has been proposed based on the results of a recent study in Bangladeshi population ${ }^{9}$. The modified equation is $\mathrm{LDLC}=\mathrm{TC}-\mathrm{TG} / 5-\mathrm{HDLC}+15.3$ (TG/TC) -2.4 (when all concentrations are expressed in $\mathrm{mg} / \mathrm{dL}$ ). Though this modification has subsequently been validated by another study in a Bangladeshi 
population $^{\mathbf{1 0}}$, it still requires more studies in different settings. The aim of this study was to examine the validity of the modified Friedewald's formula in another setting of Bangladeshi population.

\section{Materials and Methods}

This cross sectional study was conducted in the Department of Biochemistry, Chevron Clinical Laboratory, Chittagong, Bangladesh during the period of January to July, 2011. Serum TC, TG, HDLC and LDLC were measured on 1052 sera obtained from adult subjects of both sexes after 12 hours fast. Serum TG and TC were measured by enzymatic end-point method and HDLC and LDLC were measured by direct automated method using Olympus AU400 clinical chemistry analyzer (Japan). All kits, calibrators and quality control materials were purchased from Beckman, Ireland through local distributor. Thirty two subjects with serum TG concentration $>11.3 \mathrm{mmol} / \mathrm{L}$ (1000 $\mathrm{mg} / \mathrm{dL}$ ) and TG/TC $>4$ (in conventional units) were excluded. The remaining 1020 subjects were considered as study subjects. LDLC values calculated by modified Friedewald's formula (mfLDLC) and original Friedewald's formula (fLDLC) were obtained in conventional units and converted to SI units. Calculated LDLC values were compared to measured LDLC values by twotailed paired t test. Absolute bias of calculated LDLC was measured against measured LDLC. Pearson's correlation coefficient of calculated LDLC with measured LDLC and Passing \& Bablok regression equation of calculated LDLC against measured LDLC were also found out to assess the performance of modified formula against direct measurement. Statistical analyses were performed by MedCalc version 11.4 for Windows and STATISTICA version 8.0 for Windows.

\section{Results}

Mean \pm SD of age of the total study subjects was $47.1 \pm 12.9$ years, $58 \%$ subjects were males and $42 \%$ subjects were females. The mean \pm SD of lipid parameters are presented in Table I. Pearson's correlation coefficient of mf-LDLC with measured LDLC was $0.9293 \quad(p<0.0001, \quad 95 \% \quad$ CI: 0.9204 to 0.9372 ). The mean \pm SD of measured LDLC and $\mathrm{mf}-\mathrm{LDLC}$ were $2.98 \pm 0.82 \mathrm{mmol} / \mathrm{L}$ and $2.77 \pm 0.86 \mathrm{mmol} / \mathrm{L}$ respectively. Two-tailed paired $\mathrm{t}$ test showed that mf-LDLC $(\mathrm{t}=20.49, p<0.0001)$ was significantly different from measured LDLC. The mean absolute bias of mf-LDLC compared to measured LDLC (mf-LDLC-measured LDLC) was $-0.20 \pm 0.32 \mathrm{mmol} / \mathrm{L}$ (95\% CI:-0.24 to-0.19) for the modified formula (Fig 1). The mean percentage bias [(mf-LDLC-measured LDLC) $\times 100 /$ measured LDLC] was $-7.0 \pm 12.05 \%$ for the modified Friedewald's formula.

Table I: Mean \pm SD of lipid parameters

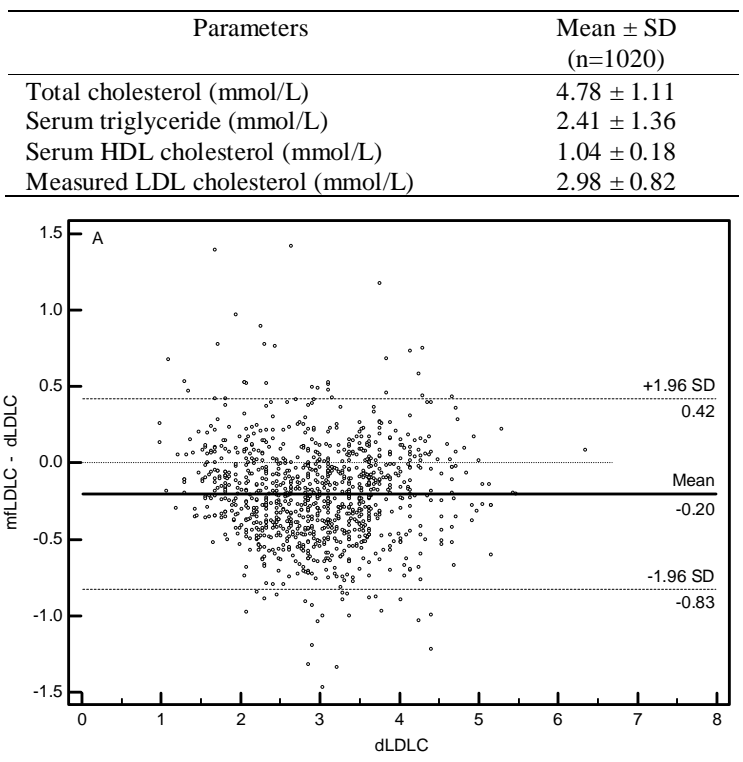

Fig 1: Bland-Altman plots for bias (calculated LDLC - measured LDLC) of mf-LDLC

Distribution of absolute differences between measured LDLC and mf-LDLC (measured LDLC mf-LDLC) showed that whole distribution is shifted slightly to the positive values from the zero point (Fig 2). A comparison of measured LDLC $(x)$ versus mf-LDLC $(y)$ yielded the regression equation: $y=-0.3856+1.0597 x$ (Fig 3). The 95\% CI of intercept and slope were -0.4587 to -0.3115 and 1.0356 to 1.0840 . The Pearson's concordance correlation coefficient $\left(\mathrm{P}_{\mathrm{c}}\right)$ of calculated LDLC was 0.9011 and the bias correction factor $\left(C_{b}\right)$, a measure of accuracy, was 0.9696 for the modified formula. The percentage bias, correlation coefficient, concordance correlation coefficient and bias correction factor for modified Friedewald's formula and original Friedewald's formula at various TG levels are shown in Table II.

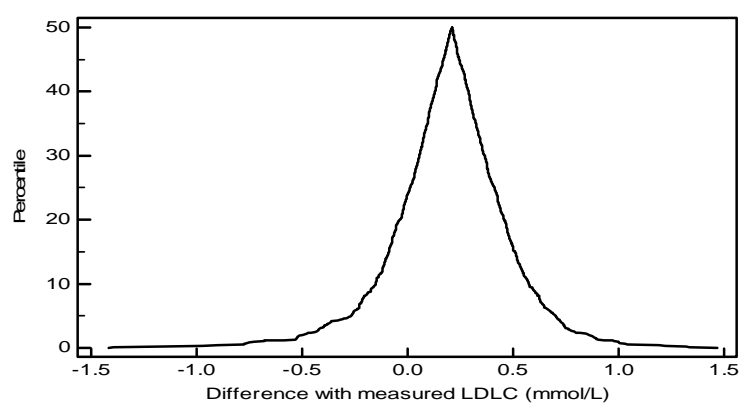

Fig. 2: Distribution of differences between measured LDLC and calculated LDLC 
The correlation coefficient of absolute bias of $\mathrm{f}$ LDLC $(\Delta \mathrm{f}=\mathrm{f}-\mathrm{LDLC}-$ measured LDLC) with TC, TG, HDLC and ratio (TG/TC) were 0.1745 $\begin{array}{llll}(p<0.0001), & -0.5710 & (p<0.0001), & 0.1847\end{array}$ $(p<0.0001)$ and $0.7153(p<0.0001)$ respectively. Multivariate linear regression analyses showed that $\beta$ values of $\Delta \mathrm{f}$ were $0.2852(p<0.0001)$ for TC, $-0.1959 \quad(p=0.0488)$ for $\mathrm{TG},-0.1741$ $(p<0.0001)$ for HDL cholesterol and -0.6035 $(p<0.0001)$ for ratio.

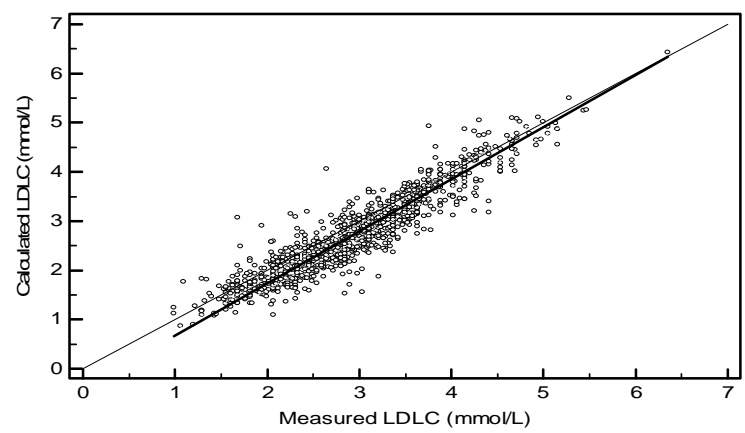

Fig 3:Passing and Bablok regression of mf-LDLC against measured LDLC

Table II: Percentage bias, Pearson's correlation coefficient, concordance correlation coefficient and bias correction factor for modified Friedewald's formula and original Friedewald's formula at various TG levels

\begin{tabular}{lcccccccccc}
\hline TG $(\mathrm{mmol} / \mathrm{L})$ & $\begin{array}{c}\text { Measured } \\
\text { LDLC }\end{array}$ & $\% \Delta \mathrm{mf}$ & $\% \Delta \mathrm{f}$ & $\begin{array}{c}r \text { for } \\
\text { mfLDLC }\end{array}$ & $\begin{array}{c}r \text { for } \\
\text { fLDLC }\end{array}$ & $\begin{array}{c}\mathrm{P}_{\mathrm{c}} \text { for } \\
\text { mfLDLC }\end{array}$ & $\begin{array}{c}\mathrm{P}_{\mathrm{c}} \text { for } \\
\text { fLDLC }\end{array}$ & $\begin{array}{c}\mathrm{C}_{\mathrm{b}} \text { for } \\
\text { mfLDLC }\end{array}$ & $\begin{array}{c}\mathrm{C}_{\mathrm{b}} \text { for } \\
\text { fLDLC }\end{array}$ \\
\hline Up to 1.13 & $2.55 \pm 0.71$ & $-7.34 \pm 9.61$ & $-3.26 \pm 9.97$ & $0.9571^{*}$ & $0.9569^{*}$ & 0.9283 & 0.9477 & 0.9699 & 0.9904 \\
$>1.13$ to 2.26 & $2.92 \pm 0.78$ & $-6.45 \pm 10.47$ & $-8.43 \pm 11.78$ & $0.9474^{*}$ & $0.9489^{*}$ & 0.9225 & 0.9113 & 0.9737 & 0.9604 & 0.973 \\
$>2.26$ to 3.39 & $3.15 \pm 0.81$ & $-6.36 \pm 10.98$ & $-14.31 \pm 14.49$ & $0.9378^{*}$ & $0.9372^{*}$ & 0.9115 & 0.8392 & 0.9719 & 0.8954 \\
$>3.39$ to 4.52 & $3.20 \pm 0.85$ & $-8.67 \pm 14.32$ & $-22.54 \pm 19.33$ & $0.9049^{*}$ & $0.9018^{*}$ & 0.8597 & 0.7142 & 0.9500 & 0.7920 \\
$>4.52$ to 11.3 & $3.07 \pm 0.84$ & $-10.47 \pm 21.52$ & $-35.31 \pm 29.45$ & $0.7823^{*}$ & $0.7704^{*}$ & 0.7233 & 0.4921 & 0.9245 & 0.6387 \\
\hline
\end{tabular}

$\% \Delta \mathrm{mf}$, (mfLDLC-measured LDLC) $\times 100 /$ measured LDLC; \% $\Delta \mathrm{f}$, (fLDLC-measured LDLC) $\times 100 /$ measured LDLC; r, Pearson's correlation coefficient; $\mathrm{P}_{\mathrm{c}}$, concordance correlation coefficient; $\mathrm{C}_{\mathrm{b}}$, bias correction factor, ${ }^{*}, \mathrm{p}<0.0001$

\section{Discussion}

In this study, we measured lipid profiles of 1020 subjects. LDLC calculated by modified Friedewald's formula correlated strongly with the measured LDLC $(r=0.9293, p<0.0001)$. In the total study subjects, the modified Friedewald's formula underestimated LDLC with absolute bias of $-0.20 \pm$ $0.32 \mathrm{mmol} / \mathrm{L}$. The distribution of absolute differences between measured LDLC and calculated LDLC showed that the whole distribution is shifted slightly to the positive direction from the zero point (Fig 2). Comparison of calculated LDLC against measured LDLC by Passing \& Bablok regression showed that the bestfit line deviated from the $45^{\circ}$ line through the origin slightly. It is also evident from the Pearson's concordance correlation coefficient that accuracy $\left(\mathrm{C}_{\mathrm{b}}\right)$ of the modified formula was 0.9696 and closer to perfect $\left(\mathrm{C}_{b}=1.0\right)$. It is also observed that the percentage bias of calculated LDLC up to TG 4.52 $\mathrm{mmol} / \mathrm{L}$ is lower for modified Friedewald's formula compared to original Friedewald's formula and the Pearson's correlation coefficient is similar. Up to serum TG level of $1.13 \mathrm{mmol} / \mathrm{L}$, the degree of pairs of observations falling on the $45^{\circ}$ line through the origin is higher for the Friedewald's formula compared to modified Friedewald's formula (0.9477 vs 0.9283$)$ and the deviation of best-fit line from the $45^{\circ}$ line through the origin is lower for original Friedewald's formula compared to modified Friedewald's formula (0.9904 vs 0.9699). Above TG concentration of $1.13 \mathrm{mmol} / \mathrm{L}$, percentage bias, concordance correlation coefficient and bias correction factor is better for modified Friedewald's formula than original Friedewald's formula.

In this study we also analyzed the relationship of absolute differences of $\mathrm{f}$-LDLC with TC, TG, HDLC and ratio (TG/TC). The correlation coefficient of absolute differences with serum TG to $\mathrm{TC}$ ratio was higher than that with $\mathrm{TG}(0.7153 \mathrm{vs}$ 0.5710). Multivariate linear regression analyses also showed a stronger relationship of absolute differences with TG to TC ratio compared to that with TG (0.6035 vs 0.1959) which may be the underlying cause of the improved performance of the modified formula.

The modified formula has been validated by a recent study in a Bangladeshi population ${ }^{\mathbf{1 0}}$. Our findings is not consistent with the previous study regarding the bias of calculated LDLC by the modified formula ${ }^{\mathbf{1 0}}$. But the percentage biases of calculated LDLC against measured LDLC were similar in different TG groups, which were greatly increased in case of original Friedewald's formula with the increase of TG. It is also apparent from the bias correction factor $\left(\mathrm{C}_{\mathrm{b}}\right)$ that the best-fit line of $\mathrm{mf}-\mathrm{LDLC}$ is closer to the $45^{\circ}$ line passing through the origin (Table II). The deviation of mf-LDLC at 
TG levels above $4.52 \mathrm{mmol} / \mathrm{L}$ is lower than that of f-LDLC and is also lower than that of f-LDL at TG concentration of 3.39 to $4.52 \mathrm{mmol} / \mathrm{L}$ (Table II). The degree of pairs of observations falling on the $45^{\circ}$ line is higher for mf-LDLC compared to $\mathrm{f}$ LDLC (Table II). Regarding percentage bias, correlation coefficient, degree of pairs of observations falling on the $45^{\circ}$ line and accuracy $\left(C_{b}\right)$, our results indicate a significant improvement of calculated LDLC by modified formula over original formula. Since only $6.7 \%$ of the study subjects had serum $\mathrm{TG}>4.52 \mathrm{mmol} / \mathrm{L}$ and mean difference is lower for modified Friedewald's formula up to serum TG concentration of 11.3 $\mathrm{mmol} / \mathrm{L}$, our data suggest the better performance of modified formula over original Friedewald's formula in Bangladeshi population.

In the present study LDL cholesterol levels calculated by modified Friedewald's formula are significantly lower than directly measured LDL cholesterol levels. But, when percentage bias, correlation coefficient (precision) and accuracy of calculated LDL cholesterol against measured LDL cholesterol are considered, the present study reveals a better performance of the modified Friedewald's formula over original Friedewald's formula for the approximate calculation of LDL cholesterol up to serum TG concentration of $11.3 \mathrm{mmol} / \mathrm{L}$. Moreover, another study ${ }^{\mathbf{1 0}}$ done in Bangladeshi population has validated the modified formula. In this perspective, we conclude that the modified Friedewald's formula can be used with caution to calculate LDL cholesterol approximately in Bangladeshi population. However, more studies in different settings are also recommended.

\section{References}

1. Cheng AY, Leiter LA. Implications of recent clinical trails for the National Cholesterol Education Program Adult Treatment Panel III guidelines. Curr Opin Cardiol 2006; 2: 400-4.
2. Executive summary of the third report of the National Cholesterol Education Programme (NCEP) Expert panel on detection, evaluation, and treatment of high blood cholesterol in adults (Adult Treatment Panel III). J Am Med Assoc 2001; 285: 2486-97.

3. Bachorick PS, Ross JW. For the National Cholesterol Education Program Working Group on Lipoprotein Measurements. National Cholesterol Education Program recommendations for measurement of lowdensity lipoprotein cholesterol: executive summary. Clin Chem 1995; 4: 1414-20.

4. Bairaktari ET, Seferiadis KI, Elisaf MS. Evaluation of Methods for the Measurement of Low-Density Lipoprotein Cholesterol. J Cardiovasc Pharmacol Therapeut 2005; 10: 45-54.

5. Nauck M, Warnick GR, Rifai N. Methods for Measurement of LDL-Cholesterol: A critical assessment of direct measurement by homogeneous assays versus calculation. Clin Chem 2002; 48: 236-54.

6. Friedewald WT, Levy RI, Fredrickson DS. Estimation of the concentration of low-density lipoprotein cholesterol in plasma, without use of the preparative ultracentrifuge. Clin Chem 1972; 18: 499-502.

7. Tremblay AJ, Morrissette H, Gagne JM, Bergeron J, Gagne C, Couture P. Validation of the Friedewald formula for the determination of low-density lipoprotein cholesterol compared with betaquantification in a large population. Clin Biochem 2004; 37: 785-90.

8. Chen Y, Zhang X, Pan B, Jin X, Yao H, Chen B, et al. A modified formula for calculating low-density lipoprotein cholesterol values. Lipids Health Disease 2010; 9:52.

9. Saiedullah M, Rahman MR, Rahman M, Khan MAH, Begum S. A simple modification of Friedewald's formula to calculate low-density lipoprotein cholesterol up to serum triglyceride concentration of $1000 \mathrm{mg} / \mathrm{dL}$. Bang J Med Biochem 2009; 2: 62-5.

10. Parvin M, Saiedullah M, Khan MAH, Rahman MR, Islam MS. Validation of the modified Friedewald's formula to calculate low-density lipoprotein cholesterol in Bangladeshi population. J Bangladesh Coll Phys Surg 2012; 30(3): 141-4. 